\title{
Research Program to Investigate the Fundamental Chemistry of Technetium
}

\author{
Lead PI: David K. Shuh, 70A-1150, Lawrence Berkeley National Laboratory, Berkeley, CA 97270
}

Co-investigators: Ian L. Pegg, Vitreous State Laboratory, The Catholic University of America, 400 Hannan Hall, 620 Michigan Avenue, NE, Washington, DC 20064

\section{Research Objectives}

Technetium $\left({ }^{99} \mathrm{Tc}\right.$, half-life $=2.13 \times 10^{5}$ years, $\beta$-emitter $)$ is one of the radionuclides of major concern for nuclear waste disposal. This concern is due to the long half-life of ${ }^{99} \mathrm{Tc}$, the ease with which pertechnetate, $\mathrm{TcO}_{4}^{-}$, migrates in the geosphere, difficulties in incorporating $\mathrm{Tc}$ into glass waste forms, and the corresponding regulatory considerations. The problem of mobility of pertechnetate in the environment is compounded by the fact that pertechnetate is the thermodynamically stable form of $\mathrm{Tc}$ in oxidizing environments. These factors present challenges for the separation and immobilization of Tc. The objective of this research project is to provide new knowledge about the chemical behavior of $\mathrm{Tc}$ so that the factors underlying its speciation in nuclear waste and in waste forms can be understood and the problems can be addressed. In particular, the behavior of Tc and $\mathrm{Re}$ in glass will be examined since $\mathrm{Re}$ is often used as a non-radioactive surrogate to predict the behavior of Tc.(1) In this project, glasses containing both Re and Tc will be prepared, so that the behavior of both metals can be compared under identical conditions

\section{Research Progress and Implications}

In the past year, glasses containing both $\mathrm{Re}$ and $\mathrm{Tc}$ have been prepared under different redox conditions using either mixtures of $\mathrm{N}_{2}$ and $\mathrm{O}_{2}$ or $\mathrm{CO}_{2}$ and $\mathrm{CO}$. The technetium and rhenium speciation was determined using X-ray absorption near edge spectroscopy (XANES). The glasses were prepared using waste surrogates and glass additives for Hanford Waste tanks AN-107 and AN105. The primary intent of these experiments was to compare the speciation of Re and Tc in glasses prepared under identical conditions (the glass samples contain both elements) to determine whether Tc and Re behave analogously during vitrification.

Figure 1 shows the Tc and Re XANES spectra for a series of glasses prepared under different redox conditions. The spectra were fit using the XANES spectra of known species as standards. The results are given in Table 1 . There is a very striking difference in the behavior of Tc and Re in this system. Although Tc(IV) can be formed during vitrification and can even be the most abundant Tc species present, $\operatorname{Re}(\mathrm{IV})$ appears to be unstable with respect to disproportionation under vitrification conditions. Under most conditions, the only Re species formed is Re(VII), and under very reducing conditions, $\operatorname{Re}(0)$ and $\operatorname{Re}(\mathrm{VII})$ are present, but $\operatorname{Re}(\mathrm{IV})$ is absent. In addition, XANES spectra of other glasses containing Re show only Re(VII) in all cases. 

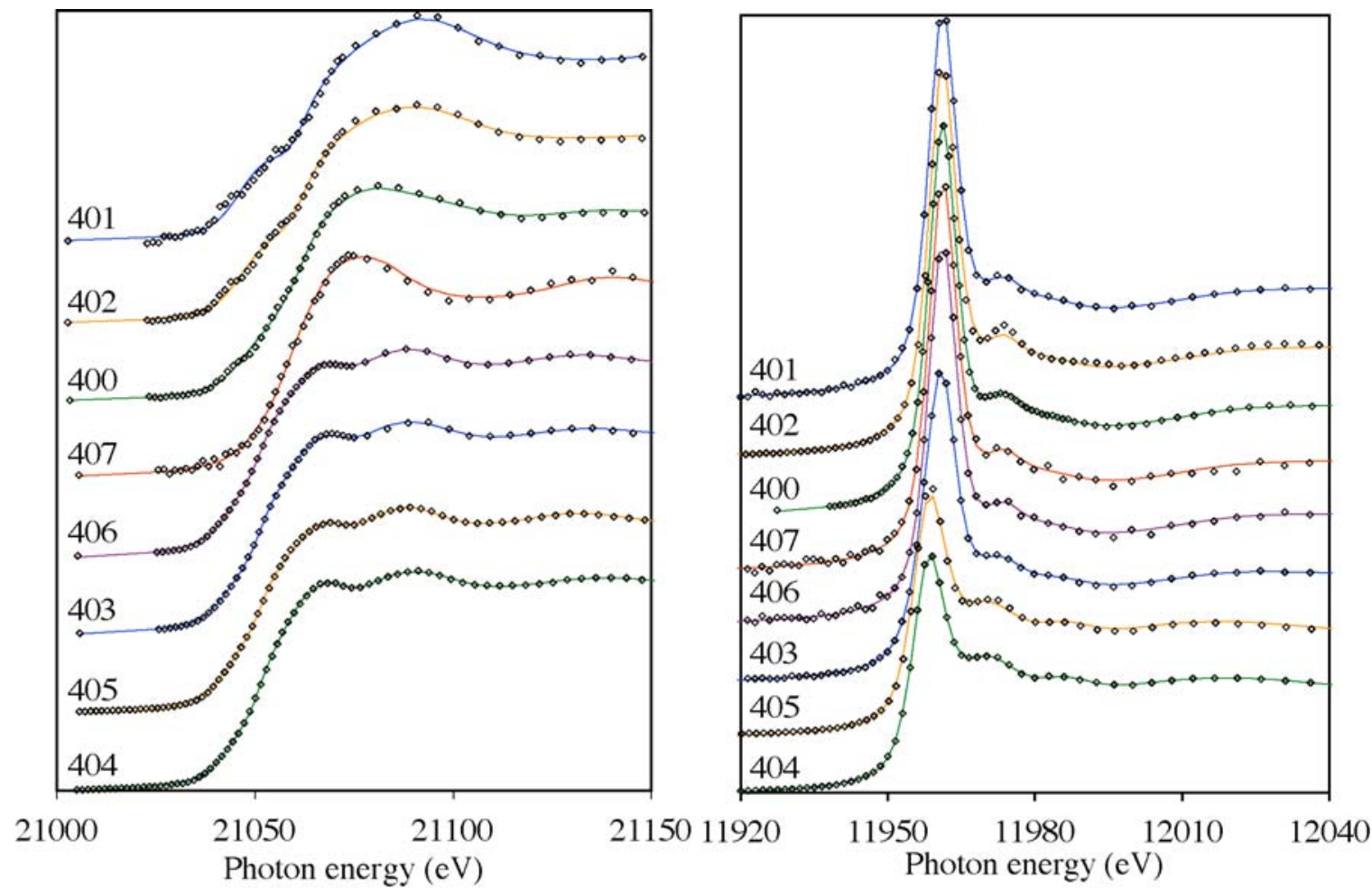

Figure 1: Tc (left) and Re(right) XANES spectra for glass samples prepared under different redox conditions, listed from most oxidizing (top) to most reducing (bottom). Sample number is given next to spectra trace. Data are indicated by diamonds, the fit is indicated by the solid line.

Table 1: Tc and Re speciation in glasses prepared under different redox conditions

\begin{tabular}{ccccccccc}
\hline Sample & Type & Gas & $\mathrm{Tc}(\mathrm{VII})^{\mathrm{a}}$ & $\mathrm{Tc}(\mathrm{IV})^{\mathrm{a}}$ & $\mathrm{Tc}(0)^{\mathrm{a}}$ & $\operatorname{Re}(\mathrm{VII})^{\mathrm{a}}$ & $\operatorname{Re}(\mathrm{VI} / \mathrm{IV})^{\mathrm{a}, \mathrm{b}}$ & $\operatorname{Re}(0)^{\mathrm{a}}$ \\
\hline 401 & $\mathrm{AN}-105$ & $\mathrm{Air}$ & 90 & 3 & 7 & 99 & 0 & 1 \\
402 & $\mathrm{AN}-105$ & $\mathrm{~N}_{2}$ & 70 & 19 & 11 & 100 & 0 & 0 \\
400 & $\mathrm{AN}-107$ & $\mathrm{Air}$ & 45 & 55 & 0 & 100 & 0 & 0 \\
407 & $\mathrm{AN}-105$ & $100 \mathrm{ppm} \mathrm{O}_{2}$ & 0 & 100 & 0 & 100 & 0 & 0 \\
406 & $\mathrm{AN}-107$ & $100 \mathrm{ppm} \mathrm{O}_{2}$ & 1 & 1 & 98 & 95 & 1 & 4 \\
403 & $\mathrm{AN}-107$ & $\mathrm{~N}_{2}$ & 3 & 2 & 95 & 60 & 0 & 40 \\
405 & $\mathrm{AN}-107$ & $\mathrm{CO} \mathrm{CO}_{2}$ & 0 & 0 & 100 & 0 & 6 & 94 \\
404 & $\mathrm{AN}-105$ & $\mathrm{CO} / \mathrm{CO}_{2}$ & 0 & 0 & 100 & 0 & 0 & 100 \\
\hline
\end{tabular}

a) Speciation is given in $\%$.

b) $\operatorname{Re}(\mathrm{IV})$ and $\operatorname{Re}(\mathrm{VI})$ fractions are summed together

These results very strongly suggest that $\operatorname{Re}(\mathrm{IV})$ is unstable towards disproportionation during vitrification while Tc(IV) is stable towards disproportionation under these conditions. Since the conditions present in the melt are sodium rich, the actual disproportionation reaction is $2 \mathrm{Na}_{2} \mathrm{SiO}_{3}+$ $7 \mathrm{MO}_{2}=3 \mathrm{M}+2 \mathrm{SiO}_{2}+4 \mathrm{NaMO}_{4}(\mathrm{M}=\mathrm{Tc}$ or Re$)$. However, thermodynamic parameters are not available for the sodium system, so the potassium system is examined instead. In addition, the heat capacities of $\mathrm{TcO}_{2}$ and $\mathrm{ReO}_{2}$ are estimated using the heat capacities (Shomate equation) of $\mathrm{MoO}_{2}$ and $\mathrm{WO}_{2}$, respectively.(2,3) Figure 2 shows the Gibbs free energy of the reaction $2 \mathrm{~K}_{2} \mathrm{SiO}_{3}+7 \mathrm{MO}_{2}=3$ $\mathrm{M}+2 \mathrm{SiO}_{2}+4 \mathrm{KMO}_{4}(\mathrm{M}=\mathrm{Tc}$ or $\mathrm{Re})$. Bearing in mind the noted estimates of some of the 
thermodynamic parameters, figure 2 clearly supports the postulate that $\operatorname{Re}(\mathrm{IV})$ is unstable towards disproportionation in the glass melt and that Tc(IV) is stable except possibly at the very highest temperature.

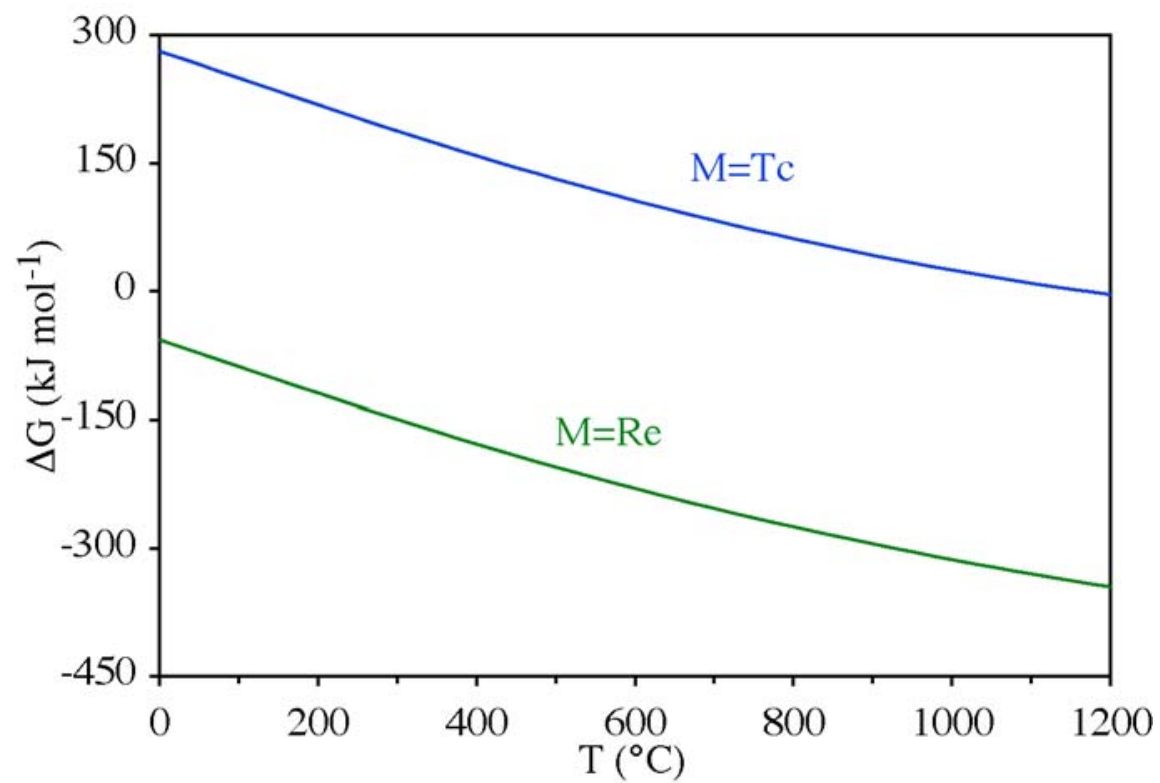

Figure 2: Gibbs free energy for the reaction $2 \mathrm{~K}_{2} \mathrm{SiO}_{3}+7 \mathrm{MO}_{2}=3 \mathrm{M}+2 \mathrm{SiO}_{2}+4 \mathrm{KMO}_{4}(\mathrm{M}=\mathrm{Tc}$ or $\mathrm{Re})$ as a function of temperature. Heat capacity was estimated using Shomate equation parameters where available.

The observation that $\operatorname{Re}(\mathrm{IV})$ is unstable towards disproportionation has implications for the use of $\mathrm{Re}$ as a surrogate for Tc in melter tests. $(1,4,5)$ Since the species responsible for technetium volatilization is most likely $\mathrm{MTcO}_{4}$, especially $\mathrm{CsTcO}_{4},(1,6)$ reduction of $\mathrm{Tc}(\mathrm{VII})$ to $\mathrm{Tc}(\mathrm{IV})$ in the glass melt would decrease the volatility of the technetium during vitrification as has been previously observed. However, Re(IV) is not accessible during vitrification. Consequently, the volatility of Re should not be greatly affected by changing redox conditions during vitrification (the very reducing conditions that result in $\operatorname{Re}(0)$ are available during vitrification of actual or simulated waste), and $\operatorname{Re}$ is probably not a useful surrogate for studying Tc volatilization. However, Re should be a conservative surrogate for Tc volatilization in that the volatilization of Re will always be greater than or equal to that of Tc.

\section{Future Work}

The relative rate of leaching of Tc and Re from glasses containing both elements will be studied. Strategies for reducing Tc volatilization by incorporating Tc in titanium or iron oxides prior to vitrification will be examined (Tc(IV) has a very similar ionic radius to $\mathrm{Ti}(\mathrm{IV})$ and $\mathrm{Fe}(\mathrm{III})$, both of which are significant components of waste glasses). 


\section{References}

(1) Darab, J. G.; Smith, P. A. Chemistry of technetium and rhenium species during lowlevel radioactive waste vitrification. Chem. Mater. 1996, 8, 1004-1021.

(2) Chase, M. W., Jr. NIST-JANAF Thermochemical tables, fourth edition. J. Phys. Chem. Ref. Data, Monograph 91998.

(3) Rard, J. A.; Rand, M. H.; Anderegg, G.; Wanner, H. Chemical Thermodynamics of Technetium; Elsevier Science: Amsterdam, 1999.

(4) McGrail, B. P.; Pierce, E. M.; Schaef, H. T.; Rodriguez, E. A.; Steele, J. L.; Owen, A. T.; Wellman, D. M. Laboratory testing of bulk vitrified and steam reformed low-activity waste forms to support a preliminary risk assessment fo $\mathrm{r}$ an integrated disposal facility. PNNL-14414, Pacific Northwest National Laboratory, Richland, WA, 2003.

(5) Kim, D. S.; Vienna, J. D.; Hrma, P. R.; Schweiger, M. J.; Matyas, J.; Crum, J. V.; Smith, D. E.; Sevigny, G. J.; Buchmiller, W. C.; J.S. Tixier, J.; Yeager, J. D.; Belew, K. B. Development and testing of ICV glasses for Hanford LAW. PNNL-14351, Pacific Northwest National Laboratory, Richland, WA, 2003.

(6) Migge, H. Simultaneous evaporation of Cs and Tc during vitrification- a thermochemical approach. Mat. Res. Soc. Symp. Proc. 1990, 176, 411-417. 